\title{
Membrane interactivity of charged local anesthetic derivative and stereoselectivity in membrane interaction of local anesthetic enantiomers
}

\author{
Hironori Tsuchiya' \\ Maki Mizogami² \\ 'Department of Dental Basic \\ Education; ${ }^{2}$ Department \\ of Anesthesiology, Asahi \\ University School of Dentistry, \\ Mizuho, Gifu, Japan
}

Correspondence: Hironori Tsuchiya Department of Dental Basic Education, Building 3,Asahi University School of Dentistry, I85I Hozumi, Mizuho, Gifu 50I-0296, Japan

Tel $+8 \mid 583291266$

Fax +8I 58329 I266

Email hiro@dent.asahi-u.ac.jp

\begin{abstract}
With respect to the membrane lipid theory as a molecular mechanism for local anesthetics, two critical subjects, the negligible effects of charged drugs when applied extracellularly and the stereoselective effects of enantiomers, were verified by paying particular attention to membrane components, phospholipids with the anionic property, and cholesterol with several chiral carbons. The membrane interactivities of structurally-different anesthetics were determined by their induced fluidity changes of liposomal membranes. Lidocaine $(3.0 \mu \mathrm{mol} / \mathrm{mL})$ fluidized phosphatidylcholine membranes, but not its quaternary derivative QX-314 (3.0 $\mu \mathrm{mol} / \mathrm{mL})$. Similarly to the mother molecule lidocaine, however, QX-314 fluidized phosphatidylserine-containing nerve cell model membranes and acidic phospholipidsconstituting membranes depending on the acidity of membrane lipids. Positively charged local anesthetics are able to act on lipid bilayers by ion-pairing with anionic (acidic) phospholipids. Bupivacaine $(0.75 \mathrm{~mol} / \mathrm{mL})$ and ropivacaine $(0.75$ and $1.0 \mu \mathrm{mol} / \mathrm{mL})$ fluidized nerve cell model membranes with the potency being $S(-)$-enantiomer $<$ racemate $<R(+)$-enantiomer $(P<0.01$, vs antipode and racemate) and cardiac cell model membranes with the potency being $S(-)$-ropivacaine $<S(-)$-bupivacaine $<R(+)$-bupivacaine $(P<0.01)$. However, their membrane effects were not different when removing cholesterol from the model membranes. Stereoselectivity is producible by cholesterol which increases the chirality of lipid bilayers and enables to discriminate anesthetic enantiomers. The membrane lipid interaction should be reevaluated as the mode of action of local anesthetics.
\end{abstract}

Keywords: local anesthetics, membrane lipid interaction, quaternary derivative, enantiomers, membrane interactivity, stereoselectivity

\section{Introduction}

The molecular mechanism underlying the effects of local anesthetics has long been a research subject of great interest in experimental and clinical anesthesiology. It is generally explained by two theories, the direct binding of drugs to receptors associated with ion channels and the perturbation by drugs of the membrane lipids surrounding functional proteins like receptors and enzymes. Since the inhibition of pharmacologicallyrelevant channels, receptors and enzymes could result from the interactions of local anesthetics with membrane proteins or membrane lipids, or both (Ragsdale et al 1996; Kopeikina et al 1997; Suwalsky et al 2002), the controversy remains regarding the primary acting site of anesthetic molecules. In recent studies, however, the membrane protein theory with specific binding sites or receptors seems to monopolize the mechanistic hypotheses for local anesthetics. This trend is attributed to the negligible effects of charged drugs when applied extracellularly (Štolc et al 1989) and the stereoselective effects of stereoisomers (Nau and Strichartz 2002), which have been exclusively interpreted by the location of receptor proteins at the cytoplasmic portion 
of transmembrane channels and by the stereospecific affinity of chiral anesthetics to receptor proteins, respectively. In the membrane protein theory, local anesthetics are considered to block voltage-gated sodium channels and affect other channel activities through the binding to receptors, reducing excitability in neuronal and cardiac tissues or causing cardiovascular malfunction (Butterworth and Strichartz 1990; Nau and Wang 2004). On the other hand, both of these pharmacological features are the objection to the membrane lipid theory in terms of the interactivity of charged anesthetics with lipid bilayers and the discrimination of membrane physicochemical changes by anesthetic stereoisomers.

Despite repulsions against the membrane lipid interaction concept, data have been suggesting the action of local anesthetics on lipid bilayers (Yun et al 2002; Högberg et al 2007; Lee et al 2008). Although the ionic analogues of local anesthetics had been recognized to be devoid of the pharmacological activity because of their membraneimpermeability, the extracellular application of quaternary lidocaine derivatives was found to affect action potentials and produce anesthesia, challenging the conventional notion that charged molecular species are ineffective when administered from the external side of cells (Štolc et al 1989; Lim et al 2007). Another support for the mechanistic interaction of anesthetics with membranes is the ability of lipid bilayers to mediate the stereoselective effects of geometrical and optical isomers (Goldstein 1984; Tsuchiya 2001a). Local anesthetics modify the membrane lipid environments, affecting the activities of receptors and ion channels through the conformational changes of such functional proteins embedded in biomembranes. Local anesthetics also penetrate into or across the lipid bilayers of cell membranes to reach the cytoplasmic binding sites on sodium channels. While class I antiarrhythmics and anticonvulsants target on the voltage-gated sodium channels similarly to local anesthetics (Ragsdale et al 1996), their charged derivatives block cardiac sodium channels from the extracellular site ( $\mathrm{Qu}$ et al 1995). In addition, the membrane protein theory does not necessarily explain the pharmacodynamic difference between bupivacaine stereoisomers (Nau et al 1999).

The aim of this study was therefore to verify the membrane lipid theory as one of pharmacological mechanisms for local anesthetics by comparatively determining their induced changes in membrane physicochemical property, fluidity. QX-314 is a quaternary derivative of lidocaine whose structural difference is only $N$-ethyl group, which renders the molecule permanently positively charged (Figure 1). Although bupivacaine has been widely marketed

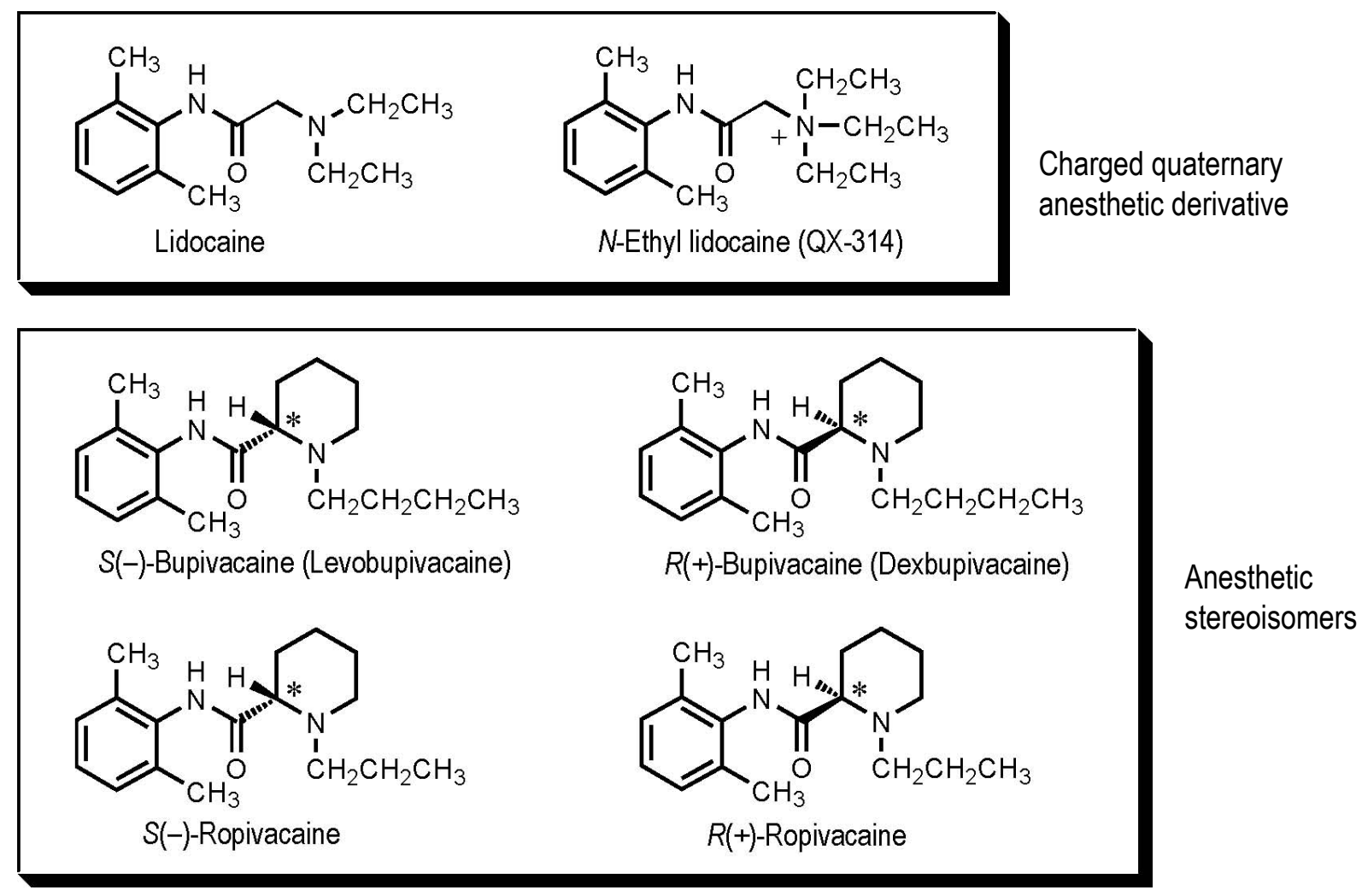

Figure I Chemical structures of quaternary derivative and stereoisomers of local anesthetics. 
as a racemic mixture of $S(-)$-bupivacaine (levorotatory configuration: levobupivacaine) and $R(+)$-bupivacaine (dextrorotatory configuration: dexbupivacaine), its adverse effects led to the development of alternative drugs, pure $S(-)$-enantiomers of ropivacaine and bupivacaine (Figure 1). These stereoisomers are discriminable in anesthetic and/or cardiotoxic potency (Heavner 2002; Nau and Strichartz 2002). The membrane-fluidizing effects of lidocaine, QX-314, $S(-)$-bupivacaine, racemic bupivacaine, $R(+)$-bupivacaine, $S(-)$-ropivacaine and $R(+)$-ropivacaine were compared to answer as to whether charged anesthetics interact with lipid bilayers and whether anesthetic enantiomers stereoselectively interact with membrane lipids.

\section{Materials and methods Chemicals}

Lidocaine hydrochloride and QX-314 (lidocaine $N$-ethyl bromide) were purchased from Sigma-Aldrich (St. Louis, MO, USA). Enantiomeric bupivacaine hydrochloride and enantiomeric ropivacaine hydrochloride were supplied by Maruishi Pharmaceutical Co. (Osaka, Japan) and AstraZeneca (Södertälje, Sweden), respectively. 1,2-Dipalmitoyl-sn-glycero-3-phosphocholine (DPPC), 1-palmitoyl-2-oleoyl-sn-glycero-3-phosphocholine (POPC), 1-palmitoyl-2-oleoyl-sn-glycero-3-phosphoethanolamine (POPE), 1-palmitoyl-2-oleoyl-sn-glycero-3-[phospho-L-serine] (POPS), 1-palmitoyl-2-oleoyl-sn-glycero-3-phosphate (POPA), 1-palmitoyl-2-oleoyl-sn-glycero-3-[phosphorac-(1-glycerol)] (POPG), cardiolipin (CL) and sphingomyelin (SM) were obtained from Avanti Polar Lipids (Alabaster, AL, USA), cholesterol from Wako Pure Chemicals (Osaka, Japan) and 1,6-diphenyl-1,3,5-hexatriene (DPH) from Molecular Probes (Eugene, OR, USA). Dimethyl sulfoxide of spectroscopic grade (Kishida, Osaka, Japan) and water of liquid chromatographic grade (Kishida) were used for preparing reagent solutions. All other chemicals were of the highest grade available commercially.

\section{Liposome preparation}

Liposomes of the lipid bilayer structure were prepared by injecting the ethanol solutions $(250 \mu \mathrm{L} \times 4)$ of phospholipids and cholesterol (total lipids of $10 \mathrm{mM})$ and DPH $(50 \mu \mathrm{M})$ into $199 \mathrm{~mL}$ of $5 \mathrm{mM}$ phosphate buffer ( $\mathrm{pH} 7.4$, containing $50 \mathrm{mM} \mathrm{NaCl}$ ) under stirring at $50{ }^{\circ} \mathrm{C}$ (Tsuchiya et al 2005). A fluorescent probe, DPH, was selectively localized into the hydrocarbon cores of lipid bilayers to reflect the membraneacting site of tested drugs. The composition of membrane lipids was $100 \mathrm{~mol} \%$ DPPC, and $60 \mathrm{~mol} \%$ POPC, POPE,
POPS, POPA, POPG, or CL with respect to $40 \mathrm{~mol} \%$ cholesterol. According to the composition of major cell membrane lipids in peripheral nerves (Svennerholm et al 1992) and hearts (Chi and Gupta 1998), nerve cell model membranes and cardiac cell model membranes were prepared with POPC, POPE, POPS, SM, and cholesterol (12 : $24: 12: 12: 40$, mol $\%$ ) and with POPC, POPE, POPS, SM, CL, and cholesterol (32.5 : $19.5: 3.25: 3.25: 6.5: 35.0$, mol\%), respectively.

\section{Membrane lipid interaction}

Local anesthetics and QX-314 dissolved in dimethyl sulfoxide were applied to membrane preparations in order to minimize the influence of added samples on reaction $\mathrm{pH}$. Their solutions were added to liposome suspensions so that the final concentration was $3.0 \mu \mathrm{mol} / \mathrm{mL}$ for lidocaine, $3.0 \mu \mathrm{mol} / \mathrm{mL}$ for QX-314, $0.75 \mu \mathrm{mol} / \mathrm{mL}$ for $S(-)$-bupivacaine, $0.75 \mu \mathrm{mol} / \mathrm{mL}$ for $R(+)$-bupivacaine, $0.75 \mathrm{~mol} / \mathrm{mL}$ for racemic bupivacaine, 0.75 and $1.0 \mu \mathrm{mol} / \mathrm{mL}$ for $S(-)$-ropivacaine, and $1.0 \mu \mathrm{mol} / \mathrm{mL}$ for $R(+)$-ropivacaine. The concentration of dimethyl sulfoxide was adjusted to be less than $0.5 \%(\mathrm{v} / \mathrm{v})$ of the total volume so as not to influence the membrane fluidity of liposomes. The reaction mixtures were incubated for $10 \mathrm{~min}$ at $37^{\circ} \mathrm{C}$. After then, the membrane-interactive potencies of the tested drugs were evaluated on the basis of membrane fluidity changes which were determined by measuring DPH fluorescence polarization using an RF-540 spectrofluorometer (Shimadzu, Kyoto, Japan) equipped with a polarizer and a cuvette thermo-controller as reported previously (Tsuchiya 2001b). Compared with controls, the decrease of polarization values means the increase of membrane fluidity (membrane fluidization).

\section{Statistical analysis}

All results are expressed as mean \pm SE $(n=6-8$ membrane experiments). Data were statistically analyzed by one-way ANOVA, followed by post-hoc Fisher's PLSD test (StatView 5.0; SAS Institute, Cary, NC, USA). $P<0.05$ was considered significant.

\section{Results}

\section{Membrane interactions of lidocaine and quaternary derivative}

Lidocaine $(3.0 \mu \mathrm{mol} / \mathrm{mL})$ acted on $100 \mathrm{~mol} \%$ DPPC liposomes to induce membrane fluidization, but not QX-314 at the same concentration (Figure 2). However, not only lidocaine but also QX-314 fluidized nerve cell model membranes with the relative potency of $1.00 \pm 0.04$ for lidocaine and $0.78 \pm 0.07$ for QX-314 based on polarization decreases. 


\section{Membrane lipid composition}

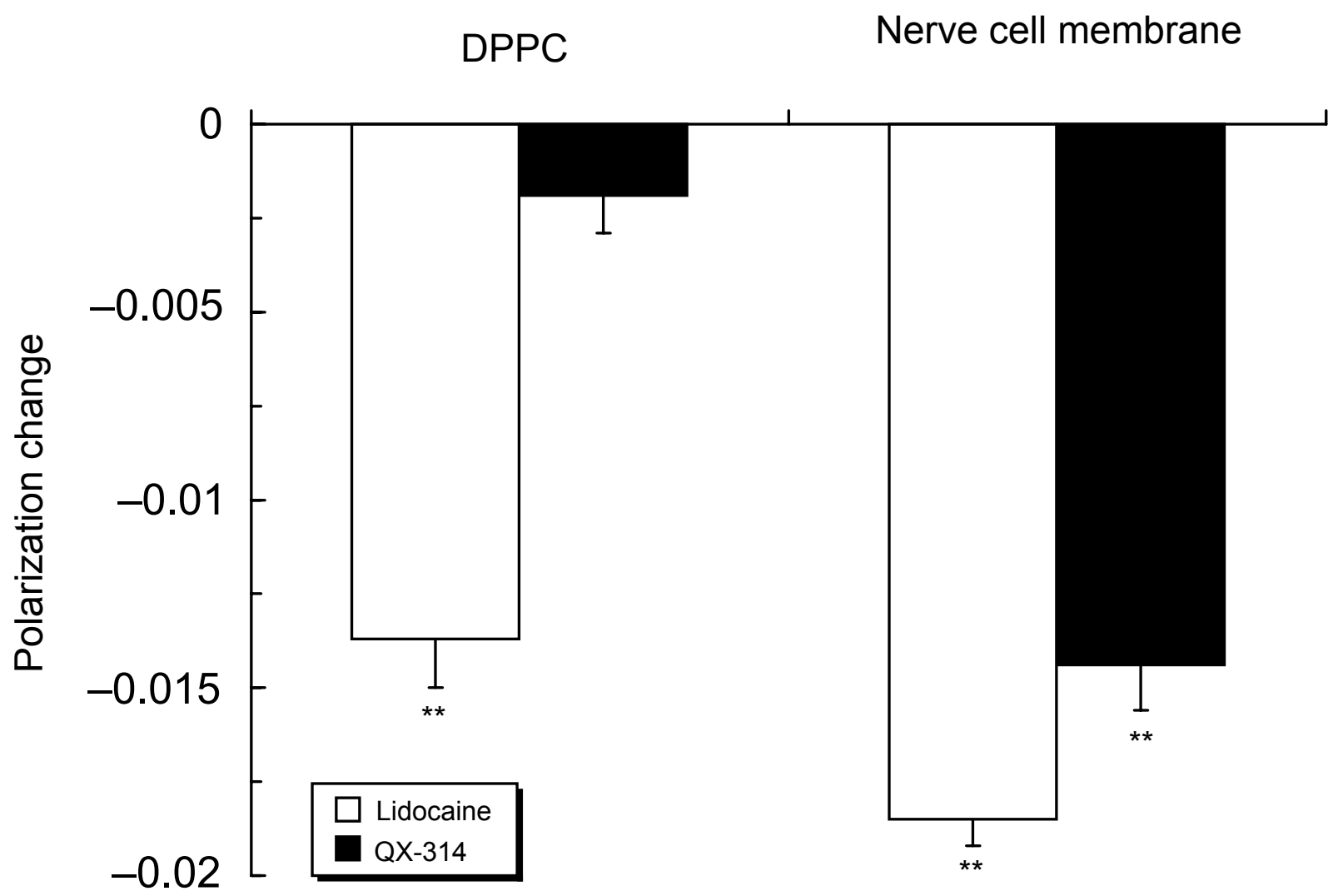

Figure 2 Interactions of lidocaine $(3.0 \mu \mathrm{mol} / \mathrm{mL})$ and QX-314 $(3.0 \mu \mathrm{mol} / \mathrm{mL})$ with $100 \mathrm{~mol} \%$ DPPC liposomal membranes and nerve cell model membranes. Notes: Data are mean \pm SE $(n=6-8)$. ${ }^{* * P}<0.01$ vs control.

Lidocaine $(3.0 \mu \mathrm{mol} / \mathrm{mL})$ was effective in fluidizing DPPC and POPC liposomal membranes, whereas QX-314 was ineffective at the same concentration (Figure 3). However, QX-314 fluidized POPS, POPA, POPG and CL liposomal membranes in increasing order of intensity as well as nerve cell model membranes containing POPS. The potencies of QX-314 to interact with these membranes were comparable or superior to those of lidocaine.

\section{Analytical precision of membrane lipid interaction}

Bupivacaine enantiomers $(0.75 \mu \mathrm{mol} / \mathrm{mL}$ for each $)$ and ropivacaine enantiomers $(0.75$ or $1.0 \mu \mathrm{mol} / \mathrm{mL}$ for each $)$ were reacted with liposomal membranes, and intra-assay $\mathrm{CVs}$ and inter-assay CVs were determined in the same membrane preparation $(n=8)$ and in different membrane preparations $(n=4)$, respectively. In nerve cell model membranes with cholesterol, intra- and inter-assay CVs were 0.83 and $0.62 \%$ for $S(-)$-bupivacaine, 0.40 and $2.37 \%$ for racemic bupivacaine, 0.54 and $1.08 \%$ for $R(+)$-bupivacaine,
0.89 and $1.16 \%$ for $S(-)$-ropivacaine, and 0.34 and $0.50 \%$ for $R(+)$-ropivacaine. In nerve cell model membranes without cholesterol, intra- and inter-assay CVs were 1.40 and $2.66 \%$ for $S(-)$-bupivacaine, 1.89 and $4.14 \%$ for racemic bupivacaine, 1.24 and $1.51 \%$ for $R(+)$-bupivacaine, 0.89 and $2.31 \%$ for $S(-)$-ropivacaine, and 1.50 and $1.79 \%$ for $R(+)$-ropivacaine. Intra-assay $\mathrm{CVs}$ showed $0.82 \%$ for $S(-)$-ropivacaine, $1.18 \%$ for $S(-)$-bupivacaine and $1.18 \%$ for $R(+)$-bupivacaine in cardiac cell model membranes with cholesterol, and $3.05 \%$ for $S(-)$-ropivacaine, $2.27 \%$ for $S(-)$-bupivacaine and $1.94 \%$ for $R(+)$-bupivacaine in ones without cholesterol.

\section{Interactions of enantiomers with nerve cell model membranes}

Bupivacaine enantiomers $(0.75 \mu \mathrm{mol} / \mathrm{mL})$ and ropivacaine enantiomers $(1.0 \mu \mathrm{mol} / \mathrm{mL})$ differentially fluidized nerve cell model membranes at the identical concentrations for each individual antipode (Figure 4). Polarization decreases showed the relative membrane interactivity being $1.00 \pm 0.13$ 


\section{Membrane lipid composition}

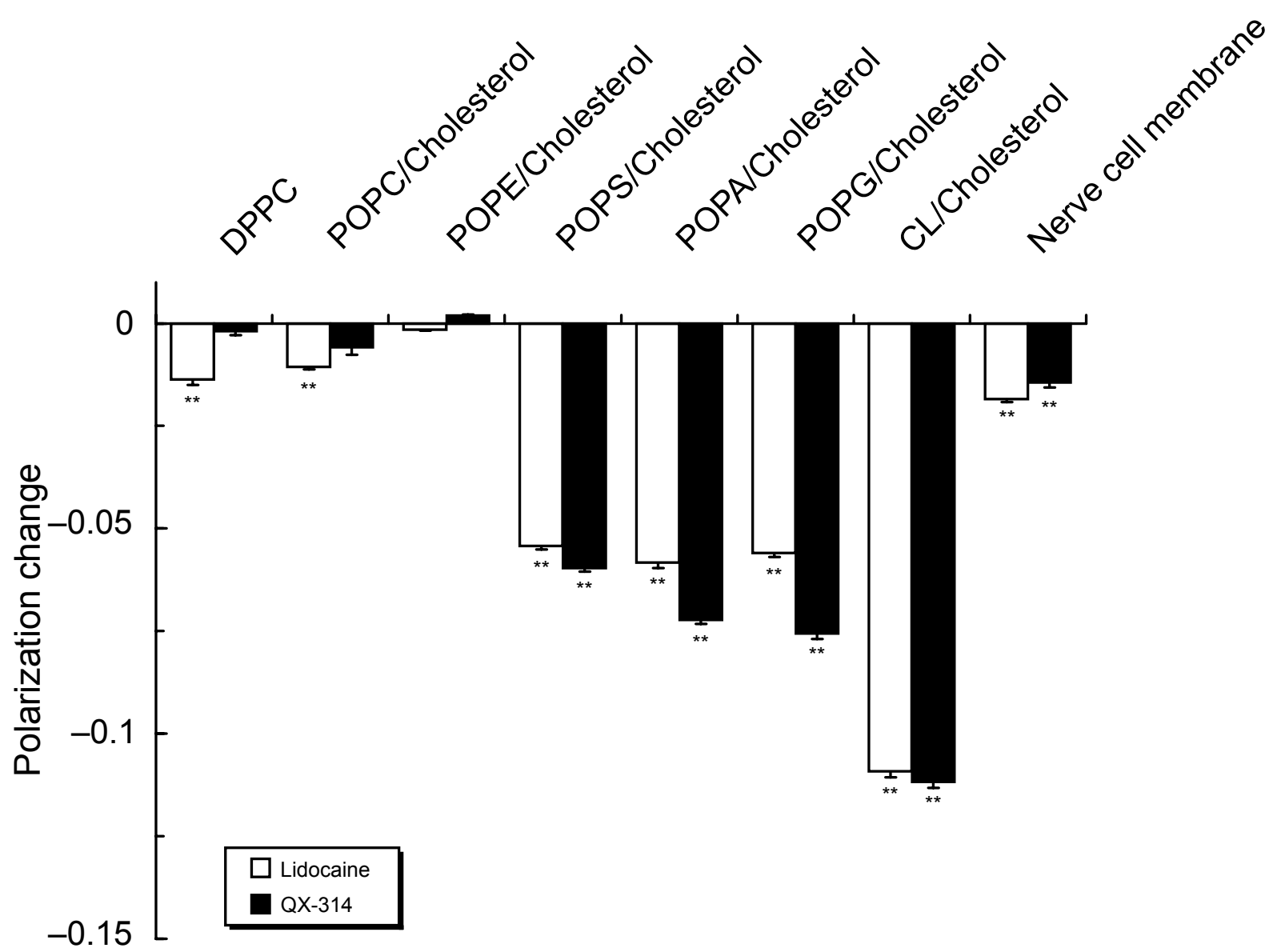

Figure 3 Interactions of lidocaine $(3.0 \mu \mathrm{mol} / \mathrm{mL})$ and QX-314 $(3.0 \mu \mathrm{mol} / \mathrm{mL})$ with liposomal membranes consisting of different phospholipids and nerve cell model membranes.

Notes: Data are mean \pm SE $(n=6-8)$. **P $<0.01$ vs control.

for $S(-)$-bupivacaine, $1.30 \pm 0.03$ for racemic bupivacaine and $1.50 \pm 0.06$ for $R(+)$-bupivacaine. In comparison of ropivacaine, the membrane-interactive potency ratio of $S(-)$-enantiomer to $R(+)$-enantiomer was $1.00 \pm 0.07: 1.37 \pm 0.03$. However, bupivacaine and ropivacaine showed no difference between stereoisomers when nerve cell model membranes were prepared without cholesterol.

\section{Comparison of interactions with cardiac cell model membranes}

The relative effects on cardiac cell model membranes were determined by the decreasing degree of polarization for the purpose of comparing bupivacaine and ropivacaine at the equimolar concentration $(0.75 \mu \mathrm{mol} / \mathrm{mL}$ for each). $S(-)$-Bupivacaine, $R(+)$-bupivacaine and $S(-)$-ropivacaine differentially fluidized cardiac cell model membranes depending on stereostructures and piperidine $N$-substituents (Figure 5). The membrane interactivity relative to $S(-)$-bupivacaine
$(1.00 \pm 0.10)$ was $1.46 \pm 0.10$ for $R(+)$-bupivacaine and $0.76 \pm 0.07$ for $S(-)$-ropivacaine. However, such difference was not found in the model membranes without cholesterol.

\section{Discussion}

Firstly, in order to verify the membrane interactivity of charged local anesthetics, lidocaine and its quaternary derivative QX-314 have been compared on their induced physicochemical changes in liposomal membranes consisting of different phospholipids. The concentrations of lidocaine typically used in the clinical setting are $1-3 \%(\mathrm{w} / \mathrm{v})$, corresponding to about $40-110 \mu \mathrm{mol} / \mathrm{mL}$ (Jastak et al 1995). At 0.03-0.08 times these concentrations, lidocaine was effective in fluidizing DPPC and POPC liposomal membranes, but not QX-314. These results are consistent with previous reports that charged local anesthetics were ineffective on cell membranes when applied externally (Štolc et al 1989; Bräu et al 1995). However, QX-314 fluidized nerve cell model 


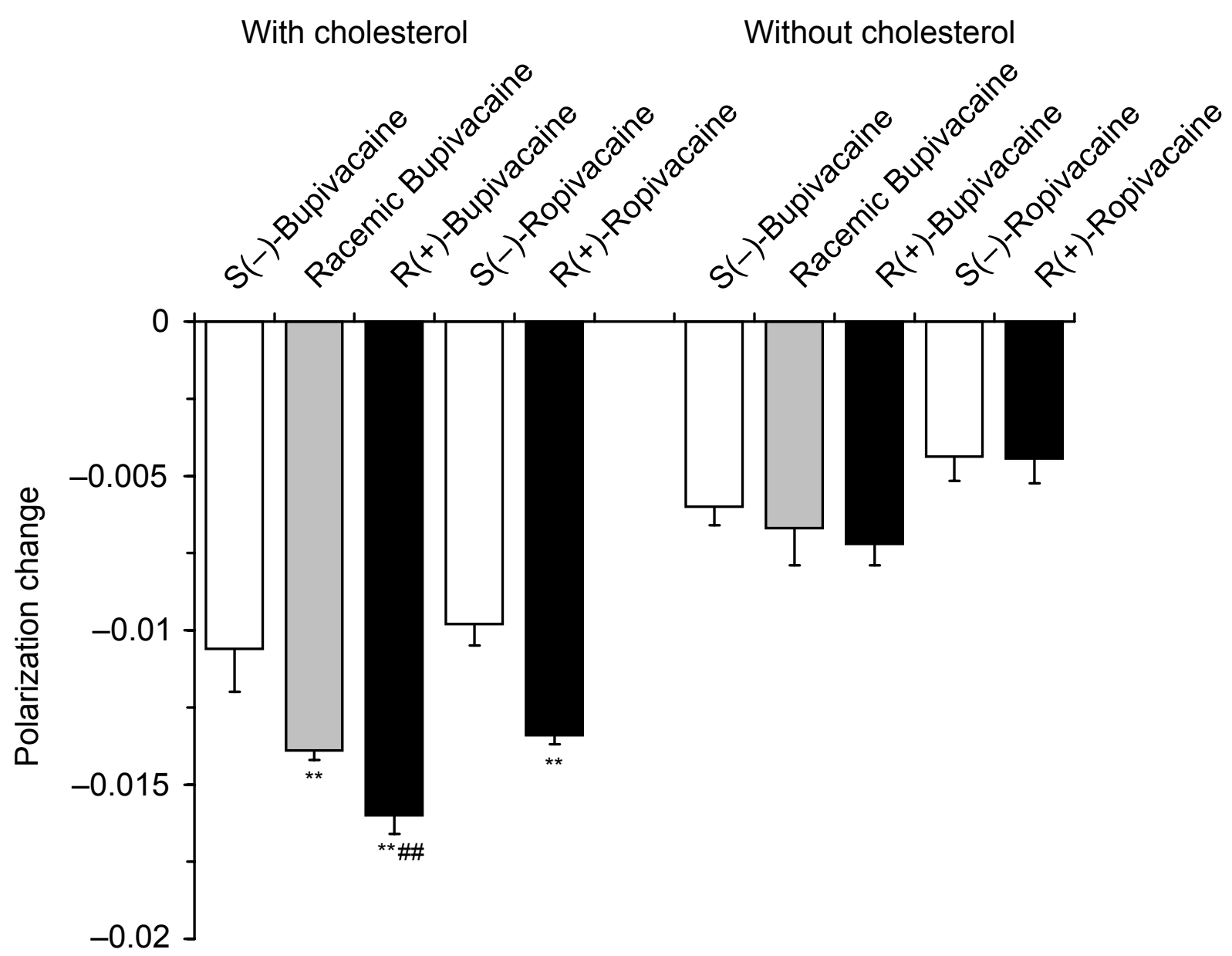

Figure 4 Interactions of bupivacaine $(0.75 \mu \mathrm{mol} / \mathrm{mL})$ and ropivacaine $(1.0 \mu \mathrm{mol} / \mathrm{mL})$ with nerve cell model membranes with and without cholesterol. Notes: Data are mean \pm SE $(n=6-8)$. $* * P<0.01$ vs each $S(-)$-enantiomer and ${ }^{\# P} P<0.01$ vs racemate.

membranes containing POPS and liposomal membranes consisting of POPS, POPA, POPG, and CL with almost the same potency as that of the mother molecule lidocaine. The conventional notion that quaternary anesthetic derivatives neither penetrate into lipid bilayers nor act on cell membranes is considered only conditional on the membrane lipid composition. The interactivity of QX-314 with membrane lipids may be also supported by the finding that it showed anesthetic and cardiac effects when applied from either side of cell membranes (Qu et al 1995; Lim et al 2007).

Amphiphilic compounds like local anesthetics affect membrane properties by the hydrophobic interaction with the aliphatic acyl chains of phospholipids and by the ionic interaction with the charged polar head-groups of phospholipids (Shimooka et al 1992). The membrane interactivities of drugs in ionic form greatly depend on membrane lipid components and their compositional ratios (Tsuchiya et al 2007). QX-314 was ineffective on zwitterionic phospholipid membranes such as DPPC, POPC, and POPE, whereas it effectively fluidized acidic phospholipid membranes such as POPS, POPA, POPG, and CL with the potency relating to their acidity. Cationic doxorubicin shows much higher affinity for anionic phospholipids than for zwitterionic phosphatidylcholine and phosphatidylethanolamine, with its positively charged amine group electrostatically bound to phospholipid head-groups and with its chromophore moiety arranged between phospholipid acyl chains (de Wolf et al 1991). While lipid bilayers are the barriers against charged or highly polar molecules, the membrane penetration of cationic peptides is mediated by negatively charged phospholipids through the formation of ion pairs (Esbjörner et al 2007). Lidocaine interacts with anionic phospholipids-containing membranes even under acidic conditions where its charged molecules predominate (Tsuchiya et al 2007). The significant difference between acidic and zwitterionic phospholipid membranes suggests that the ion-pairing is responsible for the membrane interaction of charged drug molecules. Positively-charged (cationic) local anesthetics are considered 


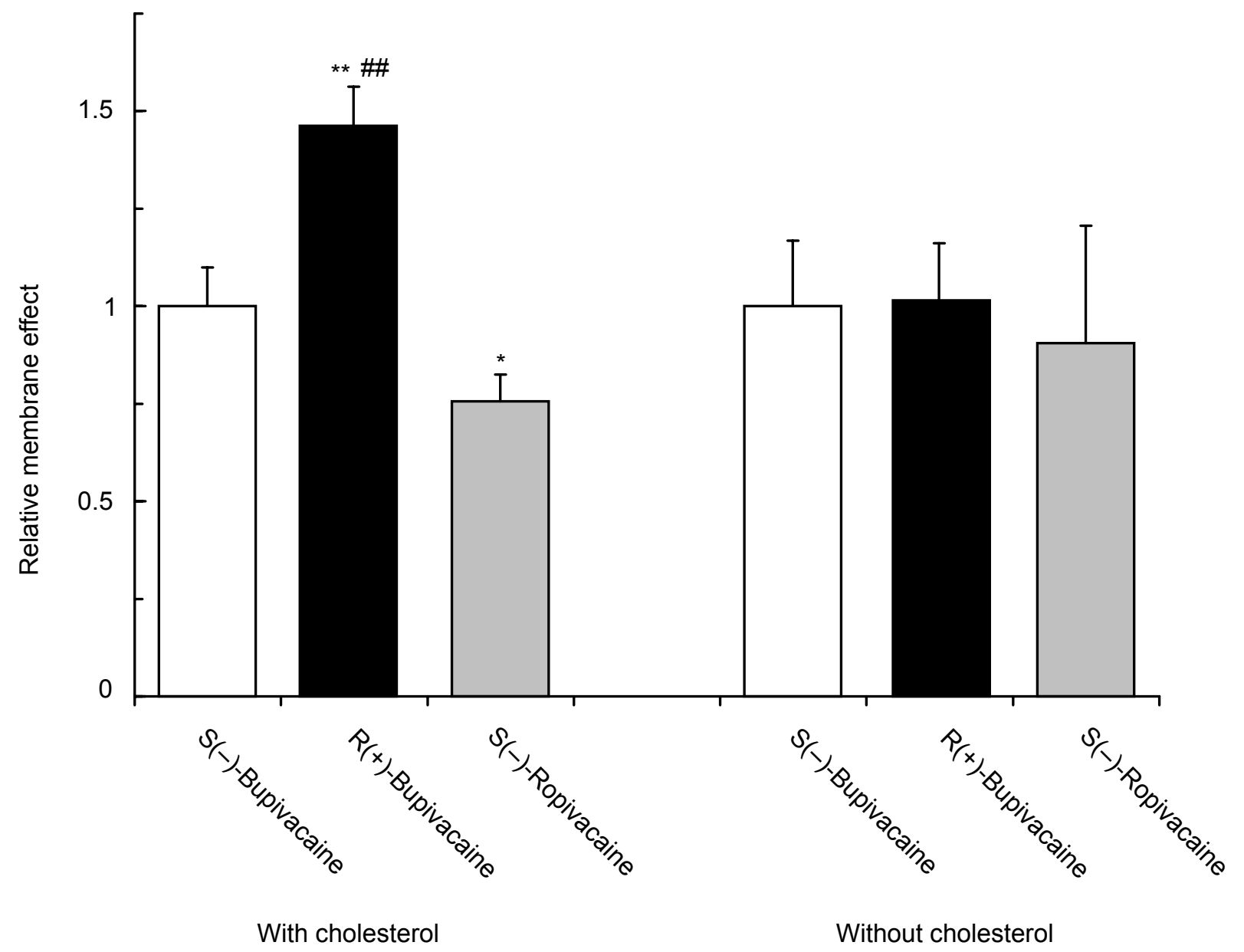

Figure 5 Comparative effects of bupivacaine and ropivacaine enantiomers $(0.75 \mu \mathrm{mol} / \mathrm{mL}$ for each $)$ on cardiac cell model membranes with and without cholesterol. Notes: Data are mean \pm SE $(n=6-8)$. $* P<0.05$ and $* * P<0.01$ vs $S(-)$-bupivacaine and ${ }^{\#} P<0.01$ vs $S(-)$-ropivacaine.

to interact with cell membranes by ion-pairing with acidic (anionic) membrane-constituting lipids like counter-ionic phosphatidylserine and cardiolipin.

Secondly, in order to verify the stereoselective membrane interaction of local anesthetic stereoisomers, the membranefluidizing effects of $S(-)$-bupivacaine and $S(-)$-ropivacaine have been compared between their enantiomers and racemate, together with specifying membrane component(s) to produce the stereoselectivity in membrane interaction. The concentrations of bupivacaine and ropivacaine commonly used for anesthesia are $0.125-0.75 \%(\mathrm{w} / \mathrm{v})$, corresponding to about 4-24 $\mu \mathrm{mol} / \mathrm{mL}$ for them (Jastak et al 1995; McClellan and Faulds 2000). At 0.03-0.25 times these concentrations, they fluidized nerve cell model membranes with the potency being $S(-)$-enantiomer $<$ racemate $<R(+)$-enantiomer. The membrane interaction assay used in this study showed so high precision that the different potencies obtained are not the experimental artifact derived from polarization measurements, conclusively indicating that the membrane interaction is discriminable between local anesthetic stereoisomers. The comparative interactivities with nerve cell model membranes are not in conflict with the pharmacological features that $S(-)$-enantiomer is less potent in analgesia than racemate and $R(+)$-enantiomer (Dyhre et al 1997; Lyons et al 1998). Local anesthetics also differentially fluidized cardiac cell model membranes to show the relative potency being $S(-)$-ropivacaine $<S(-)$-bupivacaine $<R(+)$-bupivacaine at the equimolar concentration, which was somewhat higher than the cardiotoxic concentrations of bupivacaine and ropivacaine to block cardiac sodium channels and their plasma concentrations to produce cardiac collapses (Valenzuela et al 1995; Groban et al 2001). Considering analytical precision of the membrane interaction, such results mean different membrane effects of $S(-)$-ropivacaine, $S(-)$-bupivacaine and $R(+)$-bupivacaine. Their comparative interactivities with cardiac cell model membranes are consistent with the rank order of cardiotoxicity (Morrison et al 2000; Heavner 2002) and cardiac sodium channel blockade (Valenzuela et al 1995). 
Since membrane-constituting phospholipids and cholesterol contain chiral carbons, they potentially contribute to the discrimination between local anesthetic stereoisomers (Nau and Strichartz 2002). However, stereoselectivity was found when interacting with nerve and cardiac cell model membranes in the presence of cholesterol, but not in the absence of cholesterol. A chiral carbon in the phospholipid glycerol backbone is very likely to show an achiral behavior in membrane lipid environments. Compared with phospholipids, cholesterol has more chiral carbons to increase the chirality of lipid bilayers. Therefore, cholesterol is responsible for the stereoselective membrane interaction of local anesthetics (Goldstein 1984; Tsuchiya 2001a).

It has been accepted that functional proteins are not uniformly distributed in biological membranes, but localized to the specific microdomains termed lipid rafts which are characteristically enriched in cholesterol and provide the platforms for channels and receptors (Ge et al 1999; O'Connell et al 2004). Membrane cholesterol seems to be important not only as a raft-constituting component but also as a stereoselectivity mediator for local anesthetics. The membrane interactivity was significantly increased by ion-pairing with acidic phospholipids. Cardiolipin preferentially contained in cardiac cell membranes may determine the cardiotoxic intensity of local anesthetics, while cholesterol mediates the cardiotoxic stereoselectivity (Önyüksel et al 2007).

While the clinical implication of a membrane interaction mechanism may be beyond the scope of this study, the discussion on ion pair formation and stereopotency difference would be of great value for speculating the relative benefit and risk of drugs. Local anesthetics must permeate lipoid barriers such as nerve sheaths or perineuria for reaching the nerve fibers. They also must penetrate into or across nerve and cardiac cell membranes for binding to the receptors in addition to the membrane fluidization to modify the activities of receptors and ion channels. The interactivity with lipid bilayers and/or membrane lipids is important in both pharmacokinetics and pharmacodynamics of local anesthetics. The ability of local anesthetics to form the hydrophobic ion pairs with certain anions would facilitate their diffusion into lipoid phase and their penetration into axonal and cellular membranes as well as enhance the drug delivery efficiency (Padula et al 2007). The use of appropriate counter ions may increase pharmacological effects in addition to the intrinsic activity of the formed ion pairs (Garlid and Nakashima 1983; Stolc et al 1989). In human studies, racemic bupivacaine is more potent in pain relief than $S(-)$-bupivacaine (Lyons et al 1998; Lim et al 2004). However, other comparisons of analgesic potency indicate that bupivacaine $S(-)$-enantiomer is similar to racemate and that the in vivo nerve blockade by bupivacaine is less stereospecific than the in vitro one (Vladimirov et al 2000). In contrast, the cardiotoxicity of local anesthetics consistently shows the different stereopotency (Urbanek et al 2003). $S(-)$-Ropivacine and $S(-)$-bupivacaine are less cardiotoxic than recemic bupivacaine (Foster and Markham 2000; Mather and Chang 2001), and $S(-)$-ropivacaine has a lower toxicity than $S(-)$-bupivacaine (Stienstra 2003). The stereoselectivity in membrane interaction mechanistically supports the clinical benefits of $S(-)$-enantiomeric drugs (ropivacaine and levobupivacaine) over their antipode and racemate, especially on the appearance of adverse cardiovascular effects.

In conclusion, the membrane lipid interaction can apply to the charged anesthetic molecules and account for the stereoselective effects of anesthetic stereoisomers. The membrane lipid theory should be reevaluated as one of pharmacological mechanisms for local anesthetics.

\section{Acknowledgments}

The authors thank Maruishi Pharmaceutical Co. and AstraZeneca for the supply of local anesthetic enantiomers. This study was supported by a Grant-in-Aid for Scientific Research 20592381 (to H.T.) from the Japan Society for the Promotion of Science.

\section{References}

Bräu ME, Nau C, Hempelmann G, et al. 1995. Local anesthetics potently block a potential insensitive potassium channel by myelinated nerve. J Gen Physiol, 105:485-505.

Butterworth JF, Strichartz GR. 1990. Molecular mechanisms of local anesthesia: a review. Anesthesiology, 72:711-34.

Chi Y, Gupta RK. 1998. Alterations in heart and kidney membrane phospholipids in hypertension as observed by ${ }^{31} \mathrm{P}$ nuclear magnetic resonance. Lipids, 33:1023-30.

de Wolf FA, Maliepaard M, van Dorsten F, et al. 1991. Comparable interaction of doxorubicin with various acidic phospholipids results in changes of lipid order and dynamics. Biochim Biophys Acta, 1096:67-80.

Dyhre H, Lång M, Wallin R, et al. 1997. The duration of action of bupivacaine, levobupivacaine, ropivacaine and pethidine in peripheral nerve block in the rat. Acta Anaesthesiol Scand, 41:1346-52.

Esbjörner EK, Lincoln P, Nordén B. 2007. Counterion-mediated membrane penetration: Cationic cell-penetrating peptides overcome Born energy barrier by ion-pairing with phospholipids. Biochim Biophys Acta, 1768:1550-8.

Foster RH, Markham A. 2000. Levobupivacaine: a review of its pharmacology and use as a local anaesthetic. Drugs, 59:551-79.

Garlid KD, Nakashima RA. 1983. Studies on the mechanism of uncoupling by amine local anesthetics. Evidence for mitochondrial proton transport mediated by lipophilic ion pairs. J Biol Chem, 258:7974-80.

Ge M, Field KA, Aneja R, et al. 1999. Electron spin resonance characterization of liquid ordered phase of detergent-resistant membranes from RBL-2H3 cells. Biophys J, 77:925-33.

Goldstein DB. 1984. The effects of drugs on membrane fluidity. Annu Rev Pharmacol Toxicol, 24:43-64. 
Groban L, Deal DD, Vernon JC, et al. 2001. Cardiac resuscitation after incremental overdosage with lidocaine, bupivacaine, levobupivacaine, and ropivacaine in anesthetized dogs. Anesth Analg, 92:37-43.

Heavner JE. 2002. Cardiac toxicity of local anesthetics in the intact isolated heart model: A review. Reg Anesth Pain Med, 27:545-55.

Högberg C-J, Maliniak A, Lyubartsev AP. 2007. Dynamical and structural properties of charged and uncharged lidocaine in a lipid bilayer. Biophys Chem, 125:416-24.

Jastak JT, Yagiela JA, Donaldson D. 1995. Local Anesthesia of the Oral Cavity. Philadelphia: WB Saunders.

Kopeikina LT, Kamper EF, Siafaka I, et al. 1997. Modulation of synaptosomal plasma membrane-bound enzyme activity through the perturbation of plasma membrane lipid structure by bupivacaine. Anesth Analg, 85:1337-43.

Lee J-H, Kim D-I, Mun H, et al. 2008. The effect of propoxycaine $\mathrm{HCl}$ on the physical properties of neuronal membranes. Chem Phys Lipids, 154:19-25.

Lim TKY, MacLeod BA, Ries CR, et al. 2007. The quaternary lidocaine derivative, QX-314, produces long-lasting local anesthesia in animal models in vivo. Anesthesiology, 107:305-11.

Lim Y, Ocampo CE, Sia AT. 2004. A comparison of duration of analgesia of intrathecal $2.5 \mathrm{mg}$ of bupivacaine, ropivacaine, and levobupivacaine in combined spinal epidural analgesia for patients in labor. Anesth Analg, 98:235-9.

Lyons G, Columb M, Wilson RC, et al. 1998. Epidural pain relief in labour: potencies of levobupivacaine and racemic bupivacaine. Br J Anaesth, 81:899-901.

Mather LE, Chang DH. 2001. Cardiotoxicity with modern local anaesthetics: is there a safer choice? Drugs, 61:333-42.

McClellan KJ, Faulds D. 2000. Ropivacaine: an update of its use in regional anaesthesia. Drugs, 60:1065-93.

Morrison SG, Dominguez JJ, Frascarolo P, et al. 2000. A comparison of the electrocardiographic cardiotoxic effects of racemic bupivacaine, levobupivacaine, and ropivacaine in anesthetized swine. Anesth Analg, 90:1308-14.

Nau C, Strichartz GR. 2002. Drug chirality in anesthesia. Anesthesiology, 97:497-502.

Nau C, Wang GK. 2004. Interactions of local anesthetics with voltage-gated $\mathrm{Na}^{+}$channels. J Membr Biol, 201:1-8.

Nau C, Vogel W, Hempelmann G, et al. 1999. Stereoselectivity of bupivacaine in local anesthetic-sensitive ion channels of peripheral nerve. Anesthesiology, 91:786-95.

O’Connell KMS, Martens JR, Tamkun MM. 2004. Localization of ion channels to lipid raft domains within the cardiovascular system. Trends Cardiovasc Med, 14:37-42.

Önyüksel H, Sethi V, Weinberg GL, et al. 2007. Bupivacaine, but not lidocaine, disrupts cardiolipin-containing small biomimetic unilamellar liposomes. Chem Biol Interact, 169:154-9.
Padula C, Nicoli S, Colombo P, et al. 2007. Single-layer transdermal film containing lidocaine: modulation of drug release. Eur J Pharm Biopharm, 66:422-8.

Qu Y, Rogers J, Tanada T, et al. 1995. Molecular determinants of drug access to the receptor site for antiarrhythmic drugs in the cardiac $\mathrm{Na}^{+}$ channel. Proc Natl Acad Sci US A, 92:11839-43.

Ragsdale DS, McPhee JC, Scheuer T, et al. 1996. Common molecular determinants of local anesthetic, antiarrhythmic, and anticonvulsant block of voltage-gated $\mathrm{Na}^{+}$channels. Proc Natl Acad Sci U S A, 93:9270-5.

Shimooka T, Shibata A, Terada H. 1992. The local anesthetic tetracaine destabilizes membrane structure by interaction with polar headgroups of phospholipids. Biochim Biophys Acta, 1104:261-8.

Stienstra R. 2003. The place of ropivacaine in anesthesia. Acta Anaesthesiol Belg, 54:141-8.

Štolc S, Nemček V, Szöcsová H. 1989. Local anesthetics: lipophilicity, charge, diffusion and site of action in isolated neuron. Eur J Pharmacol, 164:249-56.

Suwalsky M, Schneider C, Villena F, et al. 2002. Structural effects of the local anesthetic bupivacaine hydrochloride on the human erythrocyte membrane and molecular models. Blood Cells Mol Dis, 29:14-23.

Svennerholm L, Boström K, Fredman P, et al. 1992. Membrane lipids of human peripheral nerve and spinal cord. Biochim Biophys Acta, 1128:1-7.

Tsuchiya H. 2001a. Stereospecificity in membrane effects of catechins. Chem Biol Interact, 134:41-54.

Tsuchiya H. 2001b. Structure-specific membrane-fluidizing effect of propofol. Clin Exp Pharmacol Physiol, 28:292-9.

Tsuchiya H, Mizogami M, Takakura K. 2005. Reversed-phase liquid chromatographic retention and membrane activity relationships of local anesthetics. J Chromatogr A, 1073:303-8.

Tsuchiya H, Mizogami M, Ueno T, et al. 2007. Interaction of local anaesthetics with lipid membranes under inflammatory acidic conditions. Inflammopharmacology, 15:164-70.

Urbanek B, Duma A, Kimberger O, et al. 2003. Onset time, quality of blockade, and duration of three-in-one blocks with levobupivacaine and bupivacaine. Anesth Analg, 97:888-92.

Valenzuela C, Snyders DJ, Bennett PB, et al. 1995. Stereoselective block of cardiac sodium channels by bupivacaine in guinea pig ventricular myocytes. Circulation, 92:3014-24.

Vladimirov M, Nau C, Mok WM, et al. 2000. Potency of bupivacaine stereoisomers tested in vitro and in vivo: biochemical, electrophysiological, and neurobehavioral studies. Anesthesiology, 93:744-55.

Yun Il, Cho E-S, Jang H-O, et al. 2002. Amphiphilic effects of local anesthetics on rotational mobility in neuronal and model membranes. Biochim Biophys Acta, 1564:123-32. 
